\title{
Ethnicity, Agency, and Cultural Identity: Nexus and Difference in Australian Youth Films
}

\author{
Robyn McCallum
}

diversity, multiplicity and heterogeneity. All three films include characters who are marked as 'ethnic-Australian', but parallels between these characters and AngloAustralian characters redefine notions of cultural difference so as to encompass differences constituted by class, geographical location and physical disability, as well as racial origin. Potentially, such texts may make some progress in a redefining of the boundaries which have traditionally defined ethnic and Anglo-Celtic Australia oppositionally, and which have excluded concepts of 'ethnicity' from Anglo-Celtic experiences. However, this potential is consistent with the discursive strategies used to represent cultural difference and narrative strategies used to inscribe theme and significance. The three film texts that I discuss all utilise images of cultural diversity which are stereotyped and clichéd, and thus might be seen to be complicit in the maintenance of reified images of both Anglo-Celtic Australia and of 'ethnic' Australia. However, the films vary in the extent to which they combine these images with a self-conscious, parodic and hence interrogative approach. No Worries, for example, uses clichéd images self-consciously and in doing so implicitly calls traditional paradigms of Australian nationalism and ethnicity into question.

The multicultural issue is not the only central theme of the three films. They are also preoccupied with child/parent relationships, especially power structures within those relations, with maturation, and the conditions and limitations that sociality and the physical landscape place on childhood agency (that is the degree to which children are empowered to act independently in the world), and with alienated states of being. These themes construct a context for concerns with cultural diversity and displacement. As with literature for children, Australian films for young people have an important role in the process of cultural production in that they seek to make an impact on social formation by specifying preferred constructions of selfhood and social relations. This is especially true of films produced by the ACTF in which attempts to intervene in the process of cultural production are quite overt. Such preferred constructions of self and social relations constitute a metanarrative of subject formation which shapes the discourses of nationalism 
and multiculturalism as they are manifest in children's texts. This process occurs metonymically; that is, representations of social and cultural difference are metonymic of a larger ideology of identity formation which sees intersubjective relationships between self and other as constituting the basis for desirable and effective social and intercultural relationships. Thus, parallels between what might otherwise be thought of as quite disparate cultural groups (such as fifth generation rural Anglo-Australians and Vietnamese-Australian refugees in No Worries, for example), hinge on their similar experiences of personal displacement, social and cultural alienation and a limited sense of agency.

The metonymic structuring of issues in the three films occurs through the narrative, thematic and technical structuring of texts. The films all deal with intersections between varying social and cultural constructions of difference by drawing parallels between the social experiences of individuals with contrasting cultural backgrounds but who are similarly displaced or marginalised within mainstream Australian society. These paralleis are articulated via the narrative structuring of texts: each comprises a secondary plot centring on a character whose experience parallels that of the main character. The process of making links between the primary and secondary narratives highlights intersections between the different experiences of characters and shifts signification toward metanarratival levels of meaning. All the main characters in the three films have been displaced, either physically, culturally or socially, and they occupy alienated subject positions in relation to mainstream Australian society. Thus, each text hinges on an analogy between internal and external forms of displacement and alienation.

No Worries tells the story of the Bell family, a fifth generation Anglo-Australian farming family in northwestern New South Wales, who are forced to leave their farm by drought, a dust-storm, falling wool prices, and bank debts. They move to Sydney, to a very multicultural area of the city. The central character is a young girl, Matilda, and the film focuses on the process through which she comes to terms with what has happened to her and her parents. The latter part of the film, which is set in the city, introduces another character: Bin, a Vietnamese boat child, whose parents were killed by pirates during the journey to Australia. When Matilda runs away from home, Bin and her uncle help with the search for her, finally finding her at the sea, and the film closes with Bin and Matilda waist deep in the water, symbolically exchanging snatches of their cultural traditions.

Captain Johnno is set in the 1950 s in the small coastal fishing town of Streeton, near Adelaide, South Australia, and it is about a young profoundly deaf boy, Johnno, his difficult relationship with his father and the townspeople, and his friendship with an Italian migrant, Tony. Johnno's deafness is in part symbolic of solipsism and social alienation: he is utterly locked into a solipsistic, or selfcentred, way of viewing the world, unable often to comprehend the viewpoint of others or see the world except in terms of how it impacts on him. His limited capacity to communicate with others and to make himself understood are also indicative of the extent to which he is alienated within the small town society. He becomes friends with a young Italian migrant, Tony, who has been similarly shunned by the townsfolk. Johnno's behaviour is perceived as disruptive and anti-social (though this is largely the consequence of adults misunderstanding his actions and refusing to listen to him) and when he overhears his parents discussing whether they should send him to a special school for the deaf, Johnno runs away, sailing to a nearby island where he is later found and rescued by his new friend, Tony, the only person who, it seems, knows him well enough to have some idea of where he may have run away.

No Worries and Captain Johnno draw crosscultural parallels between different kinds of 'refugee' experiences: the experiences of first generation migrants to Australia and those of Anglo-Australians displaced or marginalised within Australian society. In contrast, a third film, On Loan, focuses more exclusively on the differing experiences of Vietnamese migrants to Australia. Lindy/ Mai is a thirteen year old Vietnamese girl, apparently orphaned, who has been raised in an Anglo-Australian family in the affluent Sydney suburb of Bondi. She receives a letter from Vietnam from her natural father, Le, who visits her, taking her to visit her Vietnamese cousins 
living in Cabramatta. Le wants Lindy to return to Vietnam with him and she finds herself having to make a choice between her Australian and Vietnamese parents and between two different cultural identities. The narrative structure of the film raises various issues. In Cabramatta Lindy meets and quickly becomes friends with her Vietnamese cousin, Minh. Both girls have been similarly displaced from their country of origin through migration, but the film contrasts the extent to which they have been culturally displaced and hence the degree to which they are aware of their own difference within Australian society. Both have been displaced physically, but whereas Minh has grown up within a predominantly Vietnamese cultural tradition, Lindy has been enculturated within an Anglo-Australian tradition. The film also makes some fairly predictable contrasts between the physical and social settings of Bondi and Cabramatta, the point being that the two girls have also been raised in quite different class cuitures.

Both No Worries and Captain Johnno construct parallels between the experiences of individuals from quite different cultural groups which are not usually depicted as comparable. The parallels between Johnno and Tony are fairly obvious, as are the thematic and ideological implications of these parallels. Technical aspects, such as camera angles and the use of reverse shots, emphasise links between them, stressing the similar marginalised positions that they both occupy. For example, early in the film there is a church service in which Tony encourages Johnno to sing. As Tony's and Johnno's loud and rather discordant voices drown out the voices of the congregation, the camera cuts between them and tracks back, contrasting their pleasure in singing with the silent response of the rest of the congregation and the priest. Reverse shots are also used to establish Johnno and Tony as primary focalisers, thus positioning the audience to view the Streeton community from their position of marginality on the fringes of a society which constructs othemess according to prejudice and misunderstanding. For example, a scene in which two boys kick Tony's fishing knife into the water echoes an earlier scene in which the same two boys tease Johnno, thereby suggesting parallels between Tony and Johnno; this earlier scene occurs just before Johnno sees Tony alighting from the bus.
Furthermore, the second scene is framed by shots of Johnno looking on. His response to the boys' actions aligns him and Tony, and it also aligns viewer point of view with both characters. Both are alienated from Streeton society as a consequence of their difference and their limited capacity to communicate and to be understood: Tony because of his limited English, and Johnno because of his speech, typical of the severely deaf. Both are treated with hostility according to stereotyped prejudices and assumptions: Johnno is assumed to be stupid as well as deaf, and the local fishermen assume that Tony poses a threat to their livelihood. The novel version of the film, a spin-off from the film, is more explicit as to their social alienation: it describes Johnno and Tony at one point as 'both of the town's outcasts' (George 1988, p.73).

A pervasive thematic interest in the film is with communication. Johnno's relations with most adults, especially his father and the teacher, are characterised by a failure in communication: they talk at him but refuse either to listen to him or allow him the opportunity to speak. The developing friendship between Tony and Johnno depends on their capacity to learn how to communicate with each other and with others. To this end the film gives emphasis to paralinguistic modes of communication; that is, communicating through gesture and physical contact. The novel places emphasis on Johnno's need to touch in order to communicate and the fact that he lives in a masculine culture which regulates and restricts physical contact. That people pull away from him when he touches them heightens his sense of his own difference (George 1988, p.18), and the narrative seems to imply that part of Johnno's interest in Tony stems from the fact that he communicates in similar ways to Johnno, through hand gestures and physical contact: 'From his hiding-place under the hay wagon, Johnno was even more interested in these Italians. He had never seen men hugging and kissing each other like that before. In Streeton a boy couldn't even touch his own father' (p.20).

In this way, the focus on communication draws parallels and implies 'natural' links between Johnno's social and physical difference and Tony's cultural difference: Johnno signs because his ability to communicate with speech is limited; Tony 'talks' with his hands because he is Italian. 
However, these parallels and the images that produce them are also instrumental in the construction of stereotyped representations of cultural difference which reify both 'Italian-Australian' culture and deaf culture. For example, in the film a short exchange between Tony and a fisherman in the pub sums up what the two characters have in common: when Tony asks 'Why you no listen t' Johnno?' he gets the response, 'Cos he's even 'arder to understand then you, ya mug'. The exchange is also interesting because it depends on clichéd cultural images. The point is that Tony speaks an Australianised version of Italian-English. Thus his 'sing-song' Italian accent and habit of waving his hands about is as much an Australian construction of 'Italianness' as the fisherman's 'Australian' accent and idiolect. Likewise, while the speech of the actor who plays Johnno is typical of that of a severely deaf child, the film reflects a 1980 s construction of 1950 s deaf culture. The style of hearing aid that Johnno wears has been in use in Australia since the 1940s, but the particular model appears very modern for the 1950s setting. This is a minor anachronism, but it highlights the extent to which Johnno's deafness is as much a textual construction as Tony's 'Italianness' and the fisherman's 'Australianness'. The film may appear to depict a reasonably accurate image of a young deaf boy's experience of 1950 s semi-rural Australian society, but it is still a representation nonetheless. At the same time, the important social functions of language and the cultural ideologies that underpin it are also given emphasis: the first sentence that Tony learns from the bus driver when he gets off the bus in Streeton is 'one schooner of beer please', a somewhat clichéd, but nonetheless effective, password into Australian male society. Similarly, Johnno's first 'Italian' word, 'squizito', accompanied by the gesture of touching the fingers to the lips, is also a cliche, but in the film its significance is also thematic. It is an aspect of cultural exchange which he learns while eating squid, or calamari, for the first time and, more importantly, it is indicative of the developing relationship between Johnno and Tony and hence of Johnno's movement out of solipsism. Through learning this word Johnno begins to gain some recognition and understanding of an other, and he continues to repeat the word in various contexts where it functions in establishing a special relationship of camaraderie between him and Tony.

No Worries is a more unusual film than Captain Johnno in that it parallels the different 'migratory' experiences of what are usually seen as quite disparate social-cultural groups: Anglo-Celtic Australians and Vietnamese boat people. In a sense Matilda and her parents are migrants within Australia, in that they migrate from the country to the city. By bringing in Bin and her uncle; and a range of other minor child characters with 'migratory' pasts, the latter part of the film makes points of intersection between the range of cultural groups that make up urban Australian society, drawing attention to the idea that Matilda's physical displacement from the country to the city also involves a degree of cultural alienation.

The discourse of No Worries is more overtly hybridised and iconic in its use of clichéd cultural images than Captain Johnno. It incorporates various iconic and archetypal images denoting 'Australianness', for example, clicherd images of the outback contrasted with the cosmopolitan city and of the country family in "the big smoke'; stereotyped constructions of 'bush life', mateship and Anglo-Australian masculinity; there are parodic references to Australian adolescent 'road' movies; and the film even opens with a game of cow pat lotto. However, the effect of all these clichés is ironic and humorous, rather than nostalgic. They construct an ideological context within which concerns with migration, displacement and ethnicity are situated, and which in turn enables a critique of traditional myths of identity. An implication of the metonymic structuring of issues at the level of a discourse which so self-consciously draws attention to its own hybridity is that traditional conceptions of ethnicity and nationalism are also indirectly challenged and dismantled.

The film has a clear two-part structure, with the first hour set in the country and last half-hour set in the city, and it sets up a series of contrasts between the country and the city. This structure is schematic, and is reminiscent of the two dominant models of nationalism described by Turner in Making it National (1994): the traditional AngloCeltic model which is informed by a nostalgia for an idealised rural colonial past and conceives of a 
homogenous society; and a newer multicultural model which stresses diversity, multiplicity and heterogeneity. The two-part structure of the film implies an almost symbolic progression from the traditional model to the contemporary model.

On the whole, the film conforms to Australian cinematic and literary traditions and implicitly idealises and privileges life in the country, but its parody, irony, and self-consciously hybridic discursive structure undercuts this. And while the city and the country are contrasted, it is not a clear-cut oppositional relation. The film works toward dismantling implicit oppositions between country and city, and between old and new, by bringing values associated with each place together. This can be seen especially in parallels between the sense of camaraderie that the farming families have with each other, and a camaraderie that Matilda's parents discover in the city when Matilda runs away, as various people around them literally drop everything to help with the search. The idea that values associated with the country can be recuperated in the city is conveyed visually at the close of the film where images of the outback are superimposed on the sea.

On Loan also draws cross-cultural parallels between Lindy/Mai's Vietnamese and Australian parents, but the focus of the film is more on Lindy's developing sense of identity as both Australian and Vietnamese. Like Captain Johnno and No Worries the discourse is hybridised, though it is much less self-reflective than either of the other films. The film opens with Lindy's performance in a concert and a short exchange between her adoptive father, Geoff, and a woman in the audience, in which the woman draws attention to Lindy's race. Geoff's response indicates that he does not differentiate between Lindy as his daughter and her racial origin; for him, the fact that she is Vietnamese is not an issue. The novel spin-off of the film places a similar emphasis on the notion that Lindy only really begins to become aware of her racial difference after she receives the first letter from her father and begins to take an interest in her past. Thus, when she goes to Cabramatta and sees so many other Vietnamese people, she feels 'oddly conscious of her race'; she finds this 'hard to get used to', 'having lived so long as part of an Australian society' (Brooksbank 1985, p.60). The opening chapters of the novel assert that Lindy does not perceive herself as different, though the narrative voice constantly asserts that she is. A strange irony occurs in the openings of the novel and the film, wherein both texts implicitly assert that Lindy's racial heritage constitutes a 'natural' or essential aspect of her difference from other (Anglo-)Australian children through reference to Western constructions of the East. In the film the concert is a performance of Tai Chi; strictly speaking, this is of course a Chinese tradition though historical connections between Vietnam and China naturalise the connection that is asserted between culture and racial origin. The novel also implies that Lindy is 'a natural' for the part that she plays when it asserts that 'she needed no stage makeup' (Brooksbank 1985. p.1). However, the concert in the novel is a performance of The Mikado, a paradigmatic Orientalist text comprising a bricolage of nineteenth century Western representations of Eastern culture. As Stephens has noted, 'there is no discernible irony' in the text of the novel, 'even though The Mikado invites reading as a work which quintessentially appropriates some forms of another culture entirely for its own purposes' (1990 p. 182). The lack of self-reflexivity here is typical of both the novel and the film, but nevertheless The Mikado reflects the focused text in its hybridity and implicit reification and cultural difference; the reference thus undermines assertions of the essentiality of difference in both texts. The discursive structuring of $O n$ Loan is as hybridised as No Worries and Captain Johnno, but it is a lot less self-conscious in its use of iconic images than either of the other texts.

The three films are all centrally concemed with questions relating to childhood agency and maturation. No Worries and Captain Johnno both combine two narrative motifs: the child running away from home as a way of dealing with events that are outside his/her control; and the development of a formative relationship with a cultural 'other'. In both films these motifs are used to produce resolutions that imply that children have limited agency, on the one hand; and on the other, that they must act in the world and take responsibility for their own lives in order to make the crucial move out of solipsism. In Captain Johnno this central message is articulated by Tony when 
he finally finds Johnno on the island. Although hungry and cold, Johnno does not want to retum home with him and Tony berates him:

Is Enough. You no run away again. No more stupid. You no think. You no think of the other people. You only think me, me, me. Only of poor deaf Johnno. Poor deaf Johnno. He make me sick. You think that life is hard. Is not only you. You think its easy for me. Nobody like me. 1 no speak good. No work. No house. My family. But I no run away. I know I must do one part more. You understand. This is what you must do. You must do one part more all the time. One part more. (Captain Johnno, videorecording, 1988)

No Worries deals with the question of agency in more complex ways by bringing together various conflicting images of Australian childhood which create a central ambivalence about the nature of agency and of childhood. On the one hand, because of the implicit idealising of life in the country Matilda is depicted as much freer there than in the city. This is given emphasis by visual contrasts between the openness of the country setting in the first part of the film and the clutter, crowds and noise in the latter part of the film. She also has a great deal more responsibility in the country than the city. She is involved in the day-to-day work of the sheep station, driving a car, helping with the shearing and so on; her capacity to participate in everyday country life implies a sense of (albeit limited) agency. On the other hand, however, she is exposed to and forced to deal with some harsh realities through which she is denied agency; for example when her father shoots the sheep he can no longer feed and subsequently shoots her dog which they can't take to the city with them. Here, and when the family is forced to leave the farm, Matilda has no part in the decisions which affect her life. Underlying this is an ambivalence about the possibility of agency itself. Matilda's life is determined by her parents, and in turn their lives are determined by the banks, political policy (the falling wool prices) and the land itself (drought, dust storms, and so on), social, economic and natural forces beyond their control. Sustained wide angle shots of the outback horizon convey in somewhat clichedd terms this sense of an inhospitable landscape. Australian myths of the individual versus the land and of Aussie battlers are never far from the surface of the film. Matilda's response to all of this is to retreat, withdraw into herself and refuse to engage with the world and other people around her. She becomes so completely wrapped up in her own grief that she is incapable of forming relationships with others. It becomes imperative then that she re-emerge from this state of withdrawal and deal with what has happened, recognise how her behaviour is affecting the people around her, and get on with life. Bin plays a small, but crucial role in facilitating Matilda's move out of solipsism, because it is in the classroom when Bin becomes visibly distressed by a picture that reminds her of the pirates who killed her parents that Matilda actually engages with and responds to an other person for the first time since her father shot her dog. As with Captain Johnno, the social setting of the two film thus plays a crucial role in determining how characters negotiate a balance between autonomy and intersubjectivity. In this way both films suggest that agency is both limited and enabled by sociality, and that it can only operate within the context of social relations.

In On Loan parallels between Lindy's Vietnamese and Australian parents emerge as they struggle over her. Insofar as these parallels function in the exploration of the larger issue of childhood agency, the similarities rather than the differences between Le and her adoptive parents are highlighted, especially in conversational exchanges in which each refers to Lindy as 'my daughter' and in scenes where characters physically position themselves in relation to Lindy, standing behind her and putting their hands on her shoulders for example. Whereas the other two films are concerned with how the development of agency depends largely on the child's capacity to move out of solipsism, in On Loan it is the parents who need to mature and hence allow Lindy to grow up. The problem for Lindy's adoptive mother and her natural father is that they see her as an extension of themselves and are unable to perceive either her point of view or each other's point of view. Marj clearly sees Le as a threat: she fears that he may attempt to take Lindy away from them. Le's position is less clear, but it is articulated in a conversation between him and his brother 
when he asserts that his brother's children will grow up to be 'Australians' and 'no longer quite your children'. It is not so much Lindy's adoptive parents who pose a threat to Le, but the culture itself; for Lindy to grow up in Australia means the loss of her Vietnamese heritage. The film undercuts both of their positions, however, mainly through Geoff's more mature acceptance of the nature of parenthood: in a conversation with Marj he asserts that 'Children are never yours for long. They are only on loan'. The film thus subscribes to an ideology of maturation which insists that parents need to move out of solipsism as much as their children in order for children to attain some degree of agency.

Finally, the choice that Lindy is forced to make between staying in Australia and retuming to Vietnam raises questions about the nature and formation of a cultural identity. She has grown up in Australian society and finally sees herself as Australian rather than Vietnamese, but at the same time her experiences in meeting her father and her cousins and learning of her past produces a certain amount of confusion for her as to "who she is and where she belongs' and makes her more aware of her own difference from both other Vietnamese-Australians and from her Anglo-Australian family and friends.

In the three films discussed here representations of social and cultural difference are ideologically shaped by an overarching metanarrative of subject formation which stresses the value of intersubjective relationships as a way of overcoming the alienation that occurs from cultural, social and physical displacement. This process occurs through the narrative, thematic and discursive structuring of texts. They each construct parallels between varying types of migration experience and varying forms of social and cultural difference and displacement. The process of making links between the various narrative strands in the films shifts signification in the direction of broader metanarratival levels of meaning, and as I have suggested the experience of cultural and social difference in each film operates metonymically to raise common questions about social and cultural alienation, relations between agency and sociality and the nature of a specifically Australian cultural identity or subjectivity. The textual discourses of the three films are overtly hybridised in their use of narrative motifs, such as the lost child, and iconic and stereotyped images of cultural identities such as 'Australian', 'Italian', 'Vietnamese-Australian', 'Vietnamese-Anglo-Australian', 'deaf', 'rural Australian', 'urban Australian' and so on. Such intertwinings of cultural definitions of 'ethnicity' and of social difference have the potential to challenge traditional paradigms of Australian national identity, as they do in No Worries. However, this potential is also limited by other discursive and narrative strategies, as well as by the degree to which texts are selfconscious and hence deliberately self-reflective in their use of such hybridic narrative forms.

\section{REFERENCES}

Brewster, Anne (1995) Literary Formations: Postcolonialism, Nationalism and Globalism. Cartton South, Victoria, Melbourne University Press.

Brooksbank, Anne (1985) On Loan. Fitzroy, Victoria, McPhee Gribble/Penguin with the Australian Children's Television Foundation.

Captain Johnno (videorecording, 1988/1992). Writer, Rob George; Director, Mario Andreacchio; Producer, Jane Ballantyne. Carlton, Victoria, The Australian Children's Television Foundation (Touch the Sun series).

George, Rob (1988) Captain Johnno. Fitzroy, Victoria, McPhee Gribble/Penguin with the Australian Children's Television Foundation.

Gunew, Sneja(1994)Framing Marginality: Multicultural Literary Studies. Carlton South, Victoria, Melboume University Press.

No Worries (1994). Screenplay, David Holman; Director, David Elfick. Palm Beach Pictures/Initial Films Production/Southern Star Entertainment, reissued as a videorecording, Sydney, Southern Star.

On Loan (videorecording, 1985/1992). Screenplay, Anne Brooksbank; Producer, Jane Scott; Director, Geoff Bennett. Carlton, Victoria, The Australian Children's Television Foundation (Winners series).

Stephens, John (1990) 'Advocating multiculturalism: 
migrants in Australian children 's literature after 1972', Childrèn's Literature Association Quarterly 15, 4, 180-188.

Turner, Graeme (1994) Making it National: Nationalism and Australian Popular Culture. Sydney, Allen and Unwin, 1994.

\section{ACKNOWLEDGMENTS}

This article was originally published in Old Neighbours New Visions: Selected Papers from the First Conference of the Australasian Children's Literature Association for Research, ed. Maureen Nimon, Centre for Children's Literature, University of South Australia, 1997.

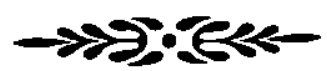

\section{BIOGRAPHICAL NOTE}

Dr Robyn McCallum is a lecturer in children's literature at Macquarie University. Her primary research interests are in adolescent fiction, picture books and children's and adolescent film and television. She is co-author, with John Stephens, of Retelling Stories, Framing Culture: Traditional Story and Metanarratives in Children's Literature, and author of Ideologies of Identity in Adolescent Fiction (forthcoming).

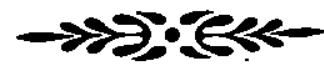

